\title{
Editorial
}

\section{Linguistic coordination: Models, dynamics and effects}

In this issue of New Ideas in Psychology we sketch a novel framework for the study of the language and psycholinguistic processes based on the idea of language as coordination dynamics. Traditionally, language has been approached as a static, closed system: either in terms of self-referential structures of arbitrary symbols and rules (Hauser, Chomsky, \& Fitch, 2002; Saussure, 1959), or of underlying modular cognitive and neurocognitive processes allowing individuals to construe and produce wellformed utterances (Cutler, Klein, \& Levinson, 2005). This has encouraged a formal approach describing language as separated from history and contexts of language use, where research was often led by abstract criteria of grammaticality and acceptability. During the last couple of decades, these approaches have been increasingly challenged. New emphases are put on the pragmatic and embodied motivations for language structure, processes and change (Fauconnier \& Turner, 2003; Lakoff \& Johnson, 1999; Langacker, 2013; Talmy, 2000). However, even these more contemporary approaches often tend to be guided by implicit and un-reflected assumptions about language as an inherently closed system relying on individual psychological processes.

The contributors to this issue of New Ideas in Psychology pursue a radically different approach, that of language as an interaction system (Bickhard, 2007a). Like any human behavior, language is considered an open, multi-modal system, deeply embedded in and shaped by continuous functional interactions with the surrounding social, cultural and material environment (Dale, Fusaroli, Duran, \& Richardson, 2014; Fusaroli, Demuru, \& Borghi, 2012; Lupyan \& Dale, 2010; Rączaszek-Leonardi \& Kelso, 2008; Tylén, Fusaroli, Bundgaard, \& Østergaard, 2013). Consequently, the study of language shifts its focus from individual inner linguistic representations to the public perceivable and communicational nature of linguistic forms (Fowler, 2013; Port, 2007). The primary goal of linguistic activity is not to construct well-formed sentences, but to maintain and regulate social affiliation and relations, share experiences and accomplish joint goals, etc. In other words, language is first and foremost a matter of coordination: coordination between interlocutors and their linguistic behaviors, between contexts and communities, between different time scales of linguistic processes, etc. (Beckner et al., 2009; Bickhard, 2009; Fusaroli \& Tylén, 2012; Greenspan \& Shanker, 2007). However, the approach to language as coordination dynamics present us with (at least) three fundamental challenges: i) How do we model language as coordination and what are the consequences? ii) If language is an open system, how do we then define and demarcate the object of scientific inquiry? iii) If grammaticality and acceptability are not by themselves the primary goals of linguistic processes how do we assess the functionality of language?

An earlier issue of New ideas in Psychology developed persuasive critiques of the formal and individualist models of language, suggesting an alternative framework based on interactions and processes (Bickhard, 2007b). The present volume presents different lines of research all resonating with and pushing forward this paradigm shift. All the contributions build on the idea that language is first and foremost a temporal process whose dynamics and effects result from activity by two or more contextually situated individuals. Consequently, dialogue is thus considered the most basic form of linguistic production. They all argue that language is a dynamic, self-organizing process of social coordination (Rączaszek-Leonardi \& Cowley, 2012). This, in effect, makes coordinative efficacy a new inquiry-leading criterion for linguistic research (Fusaroli, Bahrami, et al., 2012; Fusaroli, Gangopadhyay, \& Tylén, in review). They all, in different measures, methods and argumentations, provide attempts to address the fundamental challenges posed above.

De Beule and Stadler (in this volume) argue that the origins of many linguistic structures - such as semantic categories - lie in the self-organization processes of the organism. Relying on insights from cybernetics, they highlight how organisms interact with their environments in goal-directed ways, so to ensure the organisms' survival. Regular patterns of organism-environment interactions emerge according to affordances, that is, possibilities offered by the environment to the organism. These regular 
patterns are at the core of classification processes. Language and semantic categories are but a special case of this process: that is, emerging patterns of classification across two or more interacting organisms.

Duran and Dale (in this volume) develop the idea that low-level coordinative processes ground higher-level social and cognitive processes. They apply the HKB (Haken, Kelso, \& Bunz, 1985) dynamical model of motor coordination to describe the unfolding of conversational perspective taking in an experimental task. By taking the interaction as the basic level of analysis (rather than the individuals), the authors are able to adequately describe egocentric and other-centric response distributions, the time required for participants to enact a response on a trial-by-trial basis, and the action dynamics exhibited in individual trials. They find stabilizing patterns of social interactions analogous to the coordinative dynamics of intra-personal perceptuo-motor activity.

Fusaroli, Raczaszek-Leonardi, and Tylén (in this volume) investigate different coordinative dynamics indicative of self-organization at the level of the interaction in conversation. Expanding the current focus on alignment and behavioral synchrony, the authors outline the model of conversations as functionally driven interpersonal synergies. In order to smoothly and effectively fulfill the task at hand be it joint decision-making or casual chat - individuals tightly couple their behaviors in a context-sensitive way. Beyond selective linguistic imitation, they engage in complementary linguistic activities, distribute differentiated roles and jointly develop interactional routines.

Mills (in this volume) focuses on how interlocutors develop and negotiate interactional routines to manage the moment-by-moment coordination of utterances and actions. Relying on empirical materials from the 'maze game' (Garrod \& Anderson, 1987), the author shows that while interlocutors initially exploit partial repetitions to establish and sustain coordination, they progressively develop normative conventions and differentiate their behaviors.

Fowler (in this volume) widens the perspective from local interactions to language communities addressing the question of linguistic forms. While traditional phonological theories would define linguistic forms as mental categories, the author conceives of them as public actions, the meaning of which consists in their coordinative effects. In support of these views, the author argue that even phonological forms that could otherwise appear meaningless (in traditional accounts relying on mental lexica) often turn out to play important role in interactive encounters.

In short, the contributions to this issue articulate the key points of a new approach to language: Rather than a system 'possessed' by individual interlocutors and reflected in 'individual' linguistic behaviors, language is considered an open, interpersonal and highly situated process. This puts coordination in the heart of inquiry: multi-level behavioral synchrony, complementarity and local stabilization of interactional routines are inevitable aspects of human linguistic meaning-making. Indeed, the authors prompt us to recognize how any local linguistic phenomena (e.g. an utterance) is only appropriately considered in terms of its role as part of a larger functional assembly often comprising aspects of the social-communicative, cultural and material context. The emphasis on function is crucial in this respect.
Language is all about getting stuff done: coordinating actions and activities, solving problems, sharing experiences and maintaining affiliation (Tylén, Weed, Wallentin, Roepstorff, \& Frith, 2010). Following this line of reasoning, the object of linguistic inquiry becomes whatever resources (bodies, actions, words and objects) are recruited to the 'coordinative assembly' to fulfill a given function. Another issue relate to the particular time scales relevant for the activity at hand. Examples include local interactions, community embedded linguistic exchanges in historical time, and even evolutionary time scales. However, this does not make linguistic inquiry a hopeless enterprise without any boundaries to its object of research. On the contrary, it strongly defines the functional efficacy of the coordinative assembly as a crucial criterion to assess qualities of linguistic coordination. The meaning of linguistic forms is redefined as the coordinative effects they can have, and the adequacy of models of linguistic behavior is assessed in how well they explain and predict coordinative performance.

Crucially, the papers constituting this volume do not simply describe a state-of-the-art. They encourage further dialogue, motivate new predictions and pave the way for a novel research paradigm in the study of language, by highlighting a number of new questions to be asked: How do we describe the functionally oriented and context-sensitive structure of coordination? How do we manipulate and quantify complementary dynamics and patterns of interaction? Which physiological and cognitive mechanisms are involved in the construction of dialogical synergies and in the development and enactment of normative conventions?

\section{References}

Beckner, C., Blythe, R., Bybee, J., Christiansen, M. H., Croft, W., Ellis, N. C. et al. (2009). Language is a complex adaptive system: position paper. Language Learning, 59, 1-26.

Bickhard, M. H. (2007a). Language as an interaction system. New Ideas in Psychology, 25(2), 171-187.

Bickhard, M. H. (2007b). Modern approaches to language. New Ideas in Psychology, 25(2), 67-69.

Bickhard, M. H. (2009). The interactivist model. Synthese, 166(3), 547-591.

Cutler, A., Klein, W., \& Levinson, S. (2005). The cornerstones of twentyfirst century psycholinguistics. In A. Cutler (Ed.), Twenty-first century psycholinguistics: Four cornerstones. Mahwah, NJ: Erlbaum.

Dale, R., Fusaroli, R., Duran, N., \& Richardson, D. C. (2014). The selforganization of human interaction. Psychology of Learning and Motivation, 59, 43-96.

De Beule, J., \& Stadler, K. An evolutionary cybernetics perspective on language and coordination. New Ideas in Psychology, in this volume.

Duran, N., \& Dale, R. Perspective-taking in dialogue as self-organization under social constraints. New Ideas in Psychology, in this volume.

Fauconnier, G., \& Turner, M. (2003). The way we think: Conceptual blending and the mind's hidden complexities. New York: Basic Books.

Fowler, C. A. (2013). An ecological alternative to a "sad response": public language use transcends the boundaries of the skin. Behavioral and Brain Sciences.

Fowler, C. A. Talking as doing: language forms and public language. New Ideas in Psychology, in this volume.

Fusaroli, R., Bahrami, B., Olsen, K., Rees, G., Frith, C. D., Roepstorff, A., et al. (2012). Coming to terms: an experimental quantification of the coordinative benefits of linguistic interaction. Psychological Science, 23(8), 931-939.

Fusaroli, R., Demuru, P., \& Borghi, A. M. (2012). The intersubjectivity of embodiment. Journal of Cognitive Semiotics, 4(1).

Fusaroli, R., Gangopadhyay, N., \& Tylén, K. The dialogically extended mind: making a case for language as skilful intersubjective engagement, in review. 
Fusaroli, R., Raczaszek-Leonardi, J., \& Tylén, K. Dialogue as interpersonal synergy. New Ideas in Psychology, in this volume.

Fusaroli, R., \& Tylén, K. (2012). Carving language for social interaction: a dynamic approach. Interaction Studies, 13(1), 103-123.

Garrod, S., \& Anderson, A. (1987). Saying what you mean in dialogue: a study in conceptual and semantic co-ordination. Cognition, 27(2), 181-218.

Greenspan, S., \& Shanker, S. (2007). The developmental pathways leading to pattern recognition, joint attention, language and cognition. New Ideas in Psychology, 25(2), 128-142.

Haken, H., Kelso, J. A., \& Bunz, H. (1985). A theoretical model of phase transitions in human hand movements. Biological Cybernetics, 51(5), 347-356.

Hauser, M. D., Chomsky, N., \& Fitch, W. T. (2002). The faculty of language: what is it, who has it, and how did it evolve? Science, 298(5598), 1569-1579.

Lakoff, G., \& Johnson, M. (1999). Philosophy in the flesh. New York: Basic Books.

Langacker, R. W. (2013). Essentials of cognitive grammar. Oxford; New York: Oxford University Press.

Lupyan, G., \& Dale, R. (2010). Language structure is partly determined by social structure. PLoS One, 5(1).

Mills, G. Dialogue as joint activity: complementarity, convergence and conventionalization. New Ideas in Psychology, in this volume.

Port, R. (2007). Words, symbols, and rich memory. New Ideas in Psychology, 25(2), 143-170.
Raczaszek-Leonardi, J., \& Cowley, S. J. (2012). The evolution of language as controlled collectivity. Interaction Studies, 13(1), 1-16.

Rạczaszek-Leonardi, J., \& Kelso, J. A. S. (2008). Reconciling symbolic and dynamic aspects of language: toward a dynamic psycholinguistics. New Ideas in Psychology, 26(2), 193-207.

Saussure, F. d (1959). Course in general linguistics. New York: Philosophical Library.

Talmy, L. (2000). Toward a cognitive semantics. Cambridge, Mass.: MIT Press.

Tylén, K., Fusaroli, R., Bundgaard, P., \& Østergaard, S. (2013). Making sense together: a dynamical account of linguistic meaning making. Semiotica, 194, 1-24.

Tylén, K., Weed, E., Wallentin, M., Roepstorff, A., \& Frith, C. D. (2010). Language as a tool for interacting minds. Mind E Language, 25(1), 3-29.

R. Fusaroli*, K. Tylén Center for Semiotics, Aarhus University, Jens Chr. Skou 2, 8000 Aarhus, Denmark

Interacting Minds Center, Aarhus University, Jens Chr. Skou 2, 8000 Aarhus, Denmark

* Corresponding author. Tel.: +45 28890881. E-mail address: fusaroli@gmail.com (R. Fusaroli) 